\title{
Considerações sobre a revisão profissional de textos acadêmico-científicos
}

\author{
Renata Marques Gomide* \\ Sérgio Roberto Gomide Filho**
}

\begin{abstract}
Resumo
Este artigo propõe uma reflexão sobre a atuação do revisor de textos acadêmico-científicos, buscando contemplar tanto a questão das demandas do mercado de revisão nessa área quanto os aspectos mais amplos da prática acadêmica, que incluem não somente os procedimentos que orientam as intervenções linguístico-gramaticais dos revisores, como também as intervenções relativas à normalização e formatação dos textos - que, acredita-se, incluem um amplo conjunto de fatores, não raro decisivos para o reconhecimento de um texto como um evento comunicativo cientificamente válido. Articulada a essa reflexão está uma breve análise dos modos como quatro revisores, todos com formação em Letras e experiência no mercado de revisão de textos, conduziram suas ações em um artigo acadêmico de conclusão de curso.
\end{abstract}

Palavras-chave: Revisão. Trabalhos acadêmicos. Atuação do revisor/ preparador de textos. Normalização/formatação de textos.

Apesar da tendência de se restringir a atuação do revisor à identificação e correção de desvios gramaticais, sabe-se que a atividade de revisão de textos mobiliza uma série de estratégias linguístico-discursivas e perceptuocognitivas que vão além da adequação dos textos às normas linguísticas (ortográficas, gramaticais), ou de aspectos relativos à sua formatação e normalização. Isso pode ser atestado pelo crescente desenvolvimento de pesquisas e reflexões práticas que buscam pensar a revisão de textos como uma atividade dialógica, à luz das principais teorias acerca do engendramento social da língua/linguagem. Nesse sentido, a atividade do revisor reivindica a ativação de determinados conhecimentos e habilidades, tendo em vista diversos fatores, entre eles: a intersubjetividade da linguagem; as imagens de si e do outro construídas discursivamente; as capacidades cognitivas, como a percepção, a atenção e a memória; o dialogismo e a polifonia; as condições de produção e recepção dos textos; as injunções históricas e culturais;

* Revisora, redatora e preparadora de textos na empresa Retextualizar, Belo Horizonte, Minas Gerais.

** Centro Federal de Educação Tecnológica de Minas Gerais (CEFET-MG). 
a intertextualidade; os processos de referenciação (co e contextuais); o gênero em questão; os domínios discursivos em que o texto se situa e os demais fatores que perpassam uma situação comunicativa considerada em toda a sua complexidade.

A isso se soma o fato de que, para além dessas categorias, a esfera acadêmica demanda habilidades e conhecimentos específicos do revisor, sobretudo em relação à utilização de recursos disponibilizados pelas novas tecnologias de edição de textos, particularmente no que se refere à necessidade de reconhecer e aplicar as normas de formatação estabelecidas pelas universidades, bem como pelos principais veículos de divulgação científica. Em vista disso, o propósito deste artigo é: a) analisar e sistematizar as habilidades exigidas para a atividade profissional de revisão de textos acadêmicos; b) refletir sobre os modos de intervenção do revisor em textos técnico-científicos; e c) analisar a atuação prática do revisor no que se refere a habilidades de formatação/normalização do texto que circula no âmbito acadêmico.

Assim, o objetivo do presente artigo é refletir fundamentalmente sobre a atuação do revisor de textos acadêmico-científicos, levando em conta os aspectos mais amplos da prática acadêmica, que incluem não somente os procedimentos que orientam as intervenções linguístico-gramaticais dos revisores, como também as intervenções relativas à normalização e formatação dos textos, que incluem um amplo conjunto de fatores, não raro decisivos para o reconhecimento de um texto como um evento comunicativo cientificamente válido.

Esses aspectos são abordados, aqui, a partir da análise da atuação de quatro revisores profissionais - com formações e experiências distintas - em um único texto (um artigo científico) que apresentava problemas de diversas ordens (ortográfica, sintática, coesiva, de formatação etc.), utilizando o recurso "controlar alterações" no texto, disponibilizado pelo processador de texto Microsoft Word. ${ }^{1}$

\footnotetext{
1 Em relação à metodologia utilizada na coleta e na interpretação dos dados, cumpre pontuar, desde já, que o corpus restrito se deve à proposta reflexiva deste estudo, na intenção de uma abordagem empírica que, contudo, não pretende sistematizar ou categorizar as questões observadas, o que demandaria um estudo à parte, com um corpus significativamente mais amplo. Em vista disso, optou-se por um número reduzido de revisores, convidados a participar deste estudo em razão de sua qualificação e atuação profissional na área de revisão - à época da coleta, todos os revisores possuíam graduação e pós-graduação em Letras e atuavam no mercado de revisão há mais de dois anos.
} 


\title{
O mercado de trabalho do revisor profissional de textos acadêmicos
}

Uma rápida observação dos números relativos à produção acadêmica nacional é suficiente para evidenciar que a atividade de revisão de trabalhos acadêmicocientíficos constitui um campo de atuação em expansão, com grande potencial de mercado. Isso pode ser comprovado com base em pesquisas sobre o número crescente de textos que são publicados anualmente em revistas especializadas de divulgação científica.

\begin{abstract}
A revista britânica Times Higher Education, especializada em ensino superior e pesquisa e conhecida pela edição de rankings de universidades no mundo, divulgou, no dia 13 de dezembro de 2012, uma reportagem sobre o interesse político e acadêmico internacional nas instituições de pesquisa do Brasil. A reportagem mostra que duplicou o número de artigos de autores brasileiros entre 1997 e 2007 no Science Citation Index, da empresa Thomson Reuters, colocando o país na $13^{\mathrm{a}}$ posição entre os maiores produtores de ciência no mundo. (DOBRA..., 2013).
\end{abstract}

A última edição dos Indicadores de Ciência, Tecnologia e Inovação em São Paulo 2010, lançada pela Fapesp, em 2011, confirma essa expansão. Tal documento é um conhecido instrumento de avaliação das políticas públicas relativas à ciência $\mathrm{e}$ à pesquisa tecnológica, e conta com a colaboração de dezenas de pesquisadores de instituições de ensino superior e de pesquisa do País. Suas conclusões em relação à análise da produção científica nacional a partir de publicações em periódicos especializados apontam para dados bastante positivos nesse sentido, observando que

[...] a contribuição brasileira para a produção científica mundial indexada nas bases SCIE e SS CI passou de 1,6\% em 2002 para $1,9 \%$ em 2006. O crescimento de $43,5 \%$ no número de publicações no período foi bem superior ao crescimento mundial, de $22,7 \%$. De 13.180 publicações em 2002, o país passou para 18.915 publicações em 2006 (BRENTANI; CRUZ, 2011, p. 15).

Essas informações podem ser visualizadas no Gráfico 1: 
GRÁFICO 1 - Contribuição brasileira para as publicações mundiais indexadas nas bases SCIE e SSCI e taxa de crescimento anual - Brasil - 2002-2006

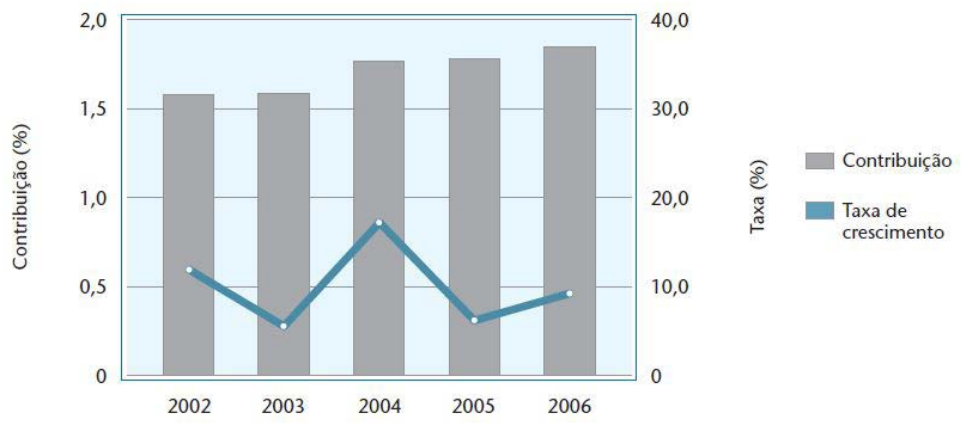

Fonte: BRENTANI; CRUZ, 2011.

Nesse cenário, a expansão do mercado de revisão profissional de textos acadêmicos está, logicamente, em relação direta com a própria expansão de publicações científicas no país. No entanto, é curioso observar a falta de incentivos para o exercício da profissão, bem como a inexistência de associações que ofereçam parâmetros e estatutos para a atuação profissional do revisor. $\mathrm{Na}$ grande maioria dos casos, revisores e preparadores de textos ou atuam de maneira informal, como prestadores de serviço, ou trabalham com carteira assinada em grandes editoras, geralmente com remuneração limitada, pelo fato de ser este um ofício sem regulamentação técnica, que pode ser (e comumente é) realizado por estudantes de graduação e/ou profissionais sem formação específica que os habilite à revisão textual.

Ainda assim, a atividade de revisão profissional de textos, como qualquer outra, configura-se a partir de demandas específicas de mercado e incorpora tais demandas ao seu modo de atuação. Por exemplo, para ser publicado, um original, de modo geral, precisa ser analisado por um preparador de textos, um revisor e um editor, profissionais que irão tratar, normalizar e adequar os originais aos propósitos da edição e ao perfil do público-alvo. Logicamente, esse processo, em última análise, depende de fatores extratextuais, como, por exemplo, a consideração dos parâmetros que regem a relação com o cliente (autor/editora), o que tem relação direta com os graus de intervenção no texto por parte do revisor/preparador. A esse respeito, Ribeiro (2008, p. 5) pontua: 
Normalização, correção ortográfica, sintática e estrutural são aspectos formais comumente tocados pelo revisor. E o conteúdo, a quem cabe? Problemas de layout dizem respeito ao revisor? Até que ponto se pode "mexer em um texto"? Quais são os limites entre retextualização, reescrita, edição e revisão? Com que intensidade pode ocorrer o diálogo entre revisor e autor? Algumas editoras mantêm certa distância entre ambos, optando pela mediação do editor. Outras instituições preferem uma negociação direta entre autor e revisor, estabelecendo entre eles uma relação de confiança.

Nos casos em que prevalece essa negociação direta entre autor e revisor, os graus de intervenção no texto apresentam grande variação: há clientes que, já de início, concedem ao revisor liberdade irrestrita; há clientes que privilegiam procedimentos de revisão relacionados a uma leitura crítica, voltada para a coerência teóricometodológica do texto; e há outros, ainda, que solicitam sinalizações de toda e qualquer alteração feita no texto para sua posterior verificação e aceitação.

De qualquer forma, o ato de preparar ou revisar um texto pressupõe sempre uma interação dialógica entre revisor/texto/autor, sem perder de vista o perfil de leitor que o próprio texto configura. Como se sabe, para o círculo bakhtiniano, bem como para toda uma gama de estudos e perspectivas que nele se fundamentam, o dialogismo é o princípio fundador da linguagem e da produção do sentido, representando uma das formas mais importantes da interação verbal: “a unidade real da língua que é realizada na fala não é a enunciação monológica individual e isolada, mas a interação de pelo menos duas enunciações, isto é, o diálogo" (BAKHTIN (VOLOCHÍNOV), 2004, p. 146).

Num sentido amplo, Bakhtin (Volochínov) (2004, p. 123) define o dialogismo "não apenas como a comunicação em voz alta, de pessoas colocadas face a face, mas toda comunicação verbal, de qualquer tipo que seja". Nessa medida, os textos/ discursos são essencialmente heterogêneos e polifônicos, sendo constituídos por relações que marcam tanto a presença de outras vozes num mesmo discurso (relações interlocutivas) quanto pelas relações que todo enunciado estabelece com aqueles anteriormente produzidos (relações interdiscursivas). Por isso, é

[...] importante notar que o profissional que trabalha sobre os textos autorais não opera como coautor; antes, produz um descentramento do texto-primeiro, que permite ao autor ser um outro desse outro de si que fez anotações pontuais como quem deixa rastros a serem seguidos. Nessas trilhas de leitura explicitadas, são feitas correções gramaticais, estabelecem-se padrões e seguem-se normas, mas esse trabalho vai muito além da ideia de corrigir, padronizar e normalizar (SALGADO, 2007, p. 16). 
Assim, não se pode desconsiderar o estilo do autor do texto a ser revisado, seu modo de posicionar-se discursivamente, suas intenções comunicativas, o jogo de vozes presente em seu texto, seus potenciais interlocutores/leitores, e, principalmente, o gênero em questão.

\section{Sobre a revisão de textos acadêmico-científicos}

Aos revisores profissionais cumpre saber intervir adequadamente no texto, conferindo uma leitura especializada e eficaz, que, de modo algum, limita-se à correção ortográfica e gramatical. Trata-se, nesse caso, de um conjunto de saberes a serem mobilizados, mesmo diante da indistinção que ainda prevalece entre atividades correlatas, como as de revisor, redator, preparador e copidesque:

No mercado editorial, ainda não se definiram distinções entre o que fazem um revisor e um redator, por exemplo, muitas vezes lugares ocupados por um mesmo profissional, que pode ser do corpo fixo da editora, um prestador de serviços ou um free lancer. Muito comumente, nos créditos de expediente mais acurados e nos cursos de formação oferecidos por entidades ligadas ao livro, o preparador de textos e o copidesque aparecem como atividades distintas, embora conexas, e o revisor trabalha na leitura final do material já diagramado, supostamente pronto para ser enviado à gráfica. Mas, na rotina dos trabalhos, nem sempre essas etapas ou esses termos são discriminados. (SALGADO, 2007, p. 141).

Vale ressaltar que as atividades do revisor e do preparador, especificamente, possuem algumas particularidades significativas. O preparador de textos, em geral, tem uma função mais ampla que a do revisor, isto é, sua intervenção no texto costuma ser maior. Ele pode fazer mais alterações no texto, propor complementações e excluir informações que julgar menos importantes. Ele também precisa verificar possíveis dificuldades de leitura e propor modificações, reescrevendo trechos, mudando parágrafos de lugar, excluindo outros, enfim, organizando os conteúdos do texto, de modo a torná-lo mais compreensível, sempre em negociação com o editor e com o autor do texto. Como bem disse Salgado (2007, p. 18), "as necessidades dos textos é que costumam guiar os preparadores".

As tarefas do revisor, por sua vez, tendem a ser mais detalhistas e discretas. Por isso, seu trabalho, no campo das práticas editoriais, muitas vezes, é realizado após as intervenções do preparador. O revisor, então, precisa ter senso crítico e 
estético em relação à estrutura e aos usos da língua portuguesa, também às normas de padronização, à correção ortográfica e ao sentido dos textos. O revisor precisa ler, entender o conteúdo e corrigir os problemas linguísticos e ortográficos ou de digitação, como letras duplicadas ou inversões indevidas; quer dizer, o revisor precisa saber como propor alterações pertinentes nos textos, cuidando para que se tornem plenamente adequados para publicação.

Salgado (2007, p. 145) destaca que, talvez, a

[...] preparação de textos pudesse referir tudo o que se faz para que um original vá a público, isto é, todos os ritos genéticos editoriais. Nesse caso, como uma expressão abarcante. Revisão de textos poderia referir especificamente à re-visão de algo que, estando pronto (já foi preparado), pede ainda um olhar rigoroso, que garanta o que foi feito na preparação (grifos da autora).

Em função de uma série de particularidades, como a demanda do autor, da editora, do prazo etc., há momentos em que o profissional do texto precisa adotar uma postura de "policial linguístico" e corrigir apenas os problemas linguísticogramaticais mesmo. Mas, quando se trata de textos acadêmicos, geralmente é preciso fazer intervenções maiores, reformulando trechos, excluindo outros, com o objetivo de que o texto se torne adequado ao que preveem as práticas discursivas usualmente privilegiadas na academia. Nesse sentido, há um inevitável imbricamento de atividades, cabendo ao revisor a realização de tarefas que, no mercado editorial, ficam a cargo do preparador. Não obstante, a atividade do revisor de textos acadêmicos reivindica, com intensidade cada vez maior, a ativação de determinados conhecimentos e habilidades relacionados aos mais amplos estratos de formatação/normalização do texto.

Em vista disso, uma questão que se coloca desde já consiste em saber até que ponto a atividade de formatação dos textos tem sido negligenciada e considerada de menor importância por parte dos próprios revisores, e até que ponto tem sido considerada, pelo crescente mercado de revisão acadêmica, como uma atividade que deveria ser plenamente incorporada à atividade de revisão.

No âmbito acadêmico, as ações agrupadas sob a designação de "formatação/ normalização" não parecem ser, sob nenhum aspecto, secundárias; pelo contrário, trata-se de uma parte importante - e, em certo sentido, inseparável - do processo de revisão como um todo. Isso porque não apenas o texto acadêmico, para ser aceito em seu meio, deve estar em conformidade com as normas técnicas de 
sua instituição, como também essas próprias normas englobam, muitas vezes, procedimentos indispensáveis à revisão acadêmica, uma vez que abrangem aspectos fundamentais para o reconhecimento do caráter "científico" do texto, como é o caso, por exemplo, das modalizações e dos mecanismos de gerenciamento de vozes.

Além disso, quando se tem em vista a necessidade de adequação da atividade de revisão às demandas do mercado, tais ações de formatação vão ao encontro das necessidades dos clientes. Note-se que, não raro, procedimentos (e treinamentos) dessa natureza são realizados majoritariamente por profissionais de biblioteconomia, o que indica, em maior ou menor grau, que a concepção de formatação/normalização como atividade secundária está presente nos próprios cursos de formação de Letras, e mesmo nos cursos de formação de revisores.

São essas mesmas demandas mercadológicas que fazem com que, na maioria das solicitações de revisão, não haja interesse do cliente por sinalizações de alterações no texto. Operando dentro de uma lógica baseada na rapidez e praticidade (a exemplo do que ocorre em boa parte das relações de mercado na sociedade contemporânea), o cliente, muitas vezes, espera que o revisor resolva os problemas que porventura forem identificados no texto - e não que o devolva com várias pendências a serem solucionadas. Dito de outro modo, em termos de relações comerciais e de demandas de mercado, não se espera do revisor uma posição à maneira de um professor, que sinaliza, explica e/ou negocia a totalidade dos termos e/ou passagens a serem reconsiderados.

Tal constatação não pretende, de modo algum, postular o enfraquecimento do diálogo com o autor, muito pelo contrário, o diálogo é fundamental e intrínseco à própria atividade de revisão, especialmente quando se tem em vista que a própria instância autoral é, em grande parte, uma construção textual-discursiva. Porém, em face da dinâmica das relações que se instauram entre revisores e clientes, cabe ao revisor determinadas tomadas de decisões das quais dependem a própria segurança passada ao cliente. Há, pois, algo da ordem de um ethos ${ }^{2}$ também construído por parte do revisor. Logicamente, por ser a revisão uma atividade fortemente dialógica, as soluções para uma melhor configuração do texto propostas pelo revisor devem ser negociadas, em função dos objetivos do texto e das necessidades do cliente.

2 "Termo emprestado da retórica antiga, o ethos (em grego $\eta \theta$ os, personagem) designa a imagem de si que o locutor constrói em seu discurso para exercer uma influência sobre seu alocutário. Essa noção foi retomada em ciências da linguagem e, principalmente, em análise do discurso, em que se refere às modalidades verbais da apresentação de si na interação verbal." (AMOSSY, 2006, p. 220, grifo da autora). 
Observe-se, contudo, que, apesar das semelhanças, provindas quase sempre do próprio campo comum de formação, a atividade do revisor é significativamente distinta da do professor de língua e com ela não se confunde. Com efeito, essa associação entre as atividades de professor e revisor não é aleatória, especialmente quando se tem em conta que o ato de revisar constitui um movimento identitário da formação em Letras. Porém, quando se tem em vista a revisão profissional de textos, há que se considerar a significativa cisão entre os papéis sociais do revisor e do professor. Nesse sentido, a própria categorização dos procedimentos de revisão precisaria, talvez, ser revista, em função não da aprendizagem da escrita (a cargo do professor de língua), mas da eficácia comunicativa do texto como um todo (sob responsabilidade do revisor profissional).

Note-se, a esse respeito, a seguinte tentativa de classificação descrita por Ribeiro (2008, p. 6):

Para Serafini (1989), as correções seriam de tipo resolutivo (quando o revisor resolve os problemas encontrados no texto), indicativo (o revisor apenas marca os problemas) e classificatório (o revisor utiliza metalinguagem para indicar os problemas). Ruiz (2001) amplia essas categorias, propondo a revisão interativa, quando o revisor dialoga com o autor, dando sugestões e discutindo aspectos do texto. Segundo as autoras, o último tipo de correção subsidia muito mais a construção da autoria e a aprendizagem da escrita.

\section{As intervenções dos revisores}

Feitas tais considerações, cumpre examinar os dados a que se relacionam as reflexões aqui empreendidas. Mais especificamente, trata-se de uma análise dos modos como quatro revisores, todos com formação em Letras e experiência no mercado de revisão de textos, conduziram suas ações em um artigo acadêmico de conclusão de curso. O artigo em questão, da área de Direito, apresenta problemas de diversas ordens, desde aspectos linguístico-gramaticais na microestrutura do texto, até aspectos macroestruturais, relacionados à adequação do texto ao gênero e, por czonseguinte, aos propósitos comunicativos que o orientam. E, relacionada à própria esfera desses propósitos, igualmente relevante é a quantidade de problemas de formatação, que abarcam não somente a formatação de páginas, parágrafos, tabulações, fontes e estilos de diagramação, como também os mecanismos de discurso reportado, que, muitas vezes, demandam uma verificação pontual das citações e referências bibliográficas. 
No caso, as seguintes questões nortearam a análise das intervenções dos revisores:

- Qual é a abrangência da revisão? Trata-se, aqui, de saber se os revisores fazem intervenções mais pontuais ou mais globais no texto, ou seja, se as intervenções são apenas ortográficas e gramaticais ou se são propostas reformulações efetivas no texto.

- Como se estabelece o diálogo entre os revisores e o autor? Nessa questão, incluem-se os aspectos relacionados não apenas ao diálogo em si, como também ao modo como os revisores posicionam-se diante dos principais problemas encontrados. Isto é, há, nos comentários dos revisores, orientações em relação à reescrita? Há explicações sobre as intervenções, ou "dicas" de escrita? Há confluência entre os papéis de revisor e de professor?

- Como os revisores procedem em relação à formatação/normalização do texto? Sob tal designação, consideram-se tanto a adequação do documento aos parâmetros gerais estabelecidos pela Associação Brasileira de Normas Técnicas (ABNT) quanto aspectos mais específicos já mencionados, a exemplo dos mecanismos de discurso reportado e gerenciamento de vozes, bem como os pontos a eles relacionados, como a verificação de citações e referências.

Quanto à primeira questão, relativa à abrangência da revisão, nota-se que, apesar de o fazerem de modos distintos, todos os revisores propõem alterações significativas no texto. Porém, os Revisores 1 (R1) e 2 (R2) detiveram-se mais nos aspectos linguístico-gramaticais:

R1:

A igualdade salarial foi implantada para evitar qualquer tratamento desigual entre os trabalhadores, Ela tem amparo constitucional por ser um relevante princípio formador do ideal democrático defendido pela ordem jurídica brasileira.

Para que a igualdade seja positivada ${ }_{2}$ devem ser levados em consideracão os aspectos Excluido: a qual das relações humanas,_formais e materiais,_e as condições jurídicas e econômicas para que seja possível atingir o bem-estar social. 
R2:

No artigo 5_ da Constituição Federal de 1988 está preconizado o princípio jurídico da igualdade, o qual preleciona que todos os indivíduos devem ser tratados igualmente perante a lei, sendo proibida a distinção de qualquer natureza Dessa maneira, é assequrada a inviolabilidade do direito à vida, à igualdade, à segurança e à propriedade a todos os brasileiros e aos estrangeiros residentes no Brasil. No direito do trabalho e nos contratos individuais de trabalho, o princípio da igualdade deve ser observado como sendo um limite da autonomia da vontade.

Excluído: proibido

Excluído:

Excluído: sendo assim

Formatado: Fonte: (Padrão) Arial

Excluído: assegurado

Excluido: a todos os brasileiros e aos estrangeiros residentes no Brasil

Excluído:

Já os Revisores 3 (R3) e 4 (R4) propuseram reformulações de trechos do texto:

R3:

A igualdade salarial possui a finalidade de evitar qualquer tratamento desigual entre os trabalhadores e tem amparo constitucional por ser um relevante princípio formador do ideal democrático defendido pela ordem jurídica brasileira.

Para que a igualdade seja positivada ${ }_{2}$ e para que seja possível atingir o bem-estar social, devem ser levados em conta os aspectos das relações humanas formais e materiais, e as condições jurídicas e econômicaş.

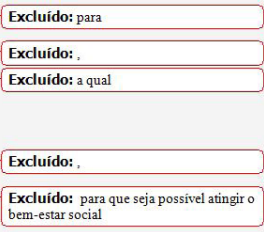

R4:

O ideal da igualdade de tratamento deve ser um fim perseguido tanto pelos trabalhadores, quanto pelos empregadores, com o apoio das entidades de classe e dos órgãos competentes de forma a permitir que haja fratamento igual para os iguais e desigual para os desiguais à medida que se desigualam.)

Excluído: o

[M3] Comentário: Trecho confuso [M3] Comentário: Trecho confuse
principalmente em "à medida que se desigualam". Reescrevê-lo.

Diretamente relacionada à primeira questão, a questão seguinte permitiu observar que, buscando estabelecer um diálogo com o autor, todos os revisores fizeram comentários sobre as intervenções realizadas por eles no texto. Em alguns casos, os comentários parecem colocar em evidência dúvidas dos revisores acerca da intencionalidade do autor em suas escolhas lexicais. Por isso, tais comentários ora buscam a simples confirmação dos elementos revisados, ora acabam chamando atenção para a própria hesitação do revisor em propor alterações. É o que se pode notar, respectivamente, nos exemplos a seguir:

\section{R1:}

Em relação ao grupo econômico que enseje solidariedade passiva e ativa (solidariedade dual) entre seus componentes, formando, dessa forma a denominação (empregador único, será possível o pedido da equiparacão em relação aos empregados vinculados a empresas distintas pertencentes ao mesmo grupo de maneira que a possibilidade | para o pleito é questão pacificada na jurisprudência.

[P7] Comentário: Favor conferir se revisei de maneira adequada esse termo. Excluído: a 
R4:

\begin{abstract}
O objetivo deste artigo é fazer uma análise crítica de uma questão controvertida e rotineira em nossos tribunais: a equiparação salarial. Tendo em vista o grande número de ações judiciais atinentes ao tema, o presente trabalho pretende abarcar as diversas questões que englobam 0 . assunto, após uma adequada exposição sobre a equiparação salarial e suas consequências. Para o desenvolvimento do estudo, são abordados os aspectos fáticos, históricos e, principalmente, jurídicos, não somente na esfera individual do empregado, mas também na esfera da relação empregatícia, assim como a posição jurisprudencial diante do quadro da equiparação salarial.
\end{abstract}

\begin{tabular}{l} 
Excluído: \\
[M1] Comentário: Substitui a \\
expressâo "a demasia". Verifique se o \\
sentido original foi mantido. \\
Excluido: a demasia \\
Excluído: o \\
Excluído: ü \\
\hline Excluído: er \\
\hline
\end{tabular}

Em outros casos, os comentários centram-se em explicações e/ou interpelações ao autor para o esclarecimento das intervenções a serem feitas:

R2:

Em relação à quarta condição, qual seja a simultaneidade no exercício funcional, encontra-se implícita na Consolidação das Leis do Trabalho, tendo-se construído essa definição a partir de jurisprudências e de doutrinas pertinentes ao assunto. Nesse sentido, a atual Súmula 6, item IV do TST L Tribunal Superior do Trabalho - regula o requisito ora em análise.

\begin{tabular}{l} 
Excluído: \\
\hline Excluído: \\
\hline [MH5] Comentário: É necessário \\
especificar a sigla na primeira vez que ela \\
apareceno texto. Quando for usá-la \\
novamente, não será mais necessário.
\end{tabular}

R3: DAMASCENO, Fernando Américo Veiga. Equiparação salarial. 2. ed. rev. e atual. São Paulo: $\mathrm{LTr}$ 1995. 272 p. ISBN 8573220600]

\begin{tabular}{l}
\hline Excluído: $\uparrow$ \\
\hline Formatado: Espaço Depois de: $0 \mathrm{pt}$, \\
Espaçamento entre inhas: simples \\
\hline [j8] Comentário: LTre euma revista ou \\
uma editora? Essa informação é \\
fundamental para "montar" estas três \\
últimas referências. \\
\hline Excluído: $\mathrm{R}$
\end{tabular}

Esse aspecto do diálogo entre o revisor e o autor é ainda mais expressivo quando os revisores fazem explicações gramaticais, atuando, de certa forma, como professores/orientadores. Nesses momentos, há uma abundância de verbos e expressões modais, o que evidencia os modos pelos quais os revisores se posicionam diante do próprio saber-fazer, como se vê nos trechos: "Aqui não pode ser plural, pois o sujeito é o trabalhador. Favor conferir..." (R1); "Todas as publicações citadas no texto devem ter seu correspondente nas referências" (R2); “[...] deve ser inserido na nota de rodapé o link completo, ou seja, que levará diretamente às informações consultadas" (R3); "O dispositivo legal a que você se refere está muito distante desta parte. Sugiro que ele seja mencionado aqui”; e "Trecho confuso principalmente em 'à medida que se desigualam'. Reescrevê-lo" (R4). 


\section{É esse o caso de boa parte dos (diversos) questionamentos e solicitações feitos} ao autor:

\section{$\mathrm{R} 1$ :}

A figura da equiparação salarial será abordada evidenciando sua importância nas relações de trabalho entre empregado e empregador, entre os empregados em sî., para toda a ordem econômica que passe a se beneficiar com o resultado de pessoal motivado, surgindo [P4] Comentário: Confuso. Năo seria: "dos empregados entre si"? então a tăo esperada harmonia na esfera laboral.

\section{R2:}

O princípio da igualdade é importante em todas as áreas da vida humana. No mercado de trabalho, em que o indivíduo vai exercer determinada profissão $e_{1} \mathrm{com}$

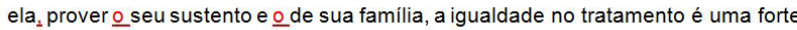
maneira de possibilitar o alcance da dignidade da pessoa humana, recompensando a todos proporcionalmente pelo seu esforço e desempenho.

[MH3] Comentário: Você diz que o principio da igualdade é importante em todas as áreas da vida humana, mas cita apenas uma área: no mercado de trabalho. Por favor, reveja.

Excluido: desempenho Excluído:

R3:

O princípio da igualdade salarial parte da premissa de que todos os homens são iguais, devendo ser igualmente remunerados quando desempenham as mesmas funções A A grandiosidade desse princípio foi acolhida por diversos dispositivos, dentre os quais podemos citar as declarações de direito internacional: Peclaração Universal dos Direitos do Homem (1948), Tratado de Versailles (1919), Convençôes $n^{\circ} 100$ e 111 , Recomendaçào $n^{\circ} 90$ da Organização Internacional do Trabalho (OIT), Pacto Internacional sobre direitos sociais, econômicos e culturais da Assembleja Geral das Nações Unidas (1966) Convenção sobre eliminação de discriminação da mulher das Nações Unidas (1979)

| 2 Disponivel em: http://pesquisasdireitodotrabalho.blogspot.com. Acesso em: 05 mar. 2013

\begin{tabular}{l}
\hline Excluído: e, \\
\hline Excluído: devem ser igualmente \\
remunerados. \\
\hline Excluído: , dentre eles pode-se \\
\hline Excluído: \\
\hline Excluído: \\
\hline Excluído: é \\
\hline [J2] Comentário: Não consegui acessar \\
o link. Além disso, deve ser inserido na \\
nota de rodapé o link completo, ou seja, \\
quelevará diretamente às informaşốes \\
consultadas. Inserir também a data correta \\
de acesso. \\
\hline Excluído: .) \\
\hline $\begin{array}{l}\text { Excluído: } \text {.HTTP//pesquisasdircitodotraba } \\
\text { lho.blogspot.com. }\end{array}$ \\
\hline Código de campo alterado \\
\hline
\end{tabular}

\section{R4:}

Sendo assim, o foco de análise serão as parcelas salariais devidas aos trabalhadores [M2] Comentário: Desta pesquisa? que exercem a mesma função, dentro de uma mesma empresa ou organização.

O ideal da igualdade de tratamento deve ser um fim perseguido tanto pelos trabalhadores, quanto pelos empregadores, com o apoio das entidades de classe e dos órgãos competentes de forma a permitir que haja tratamento igual para os iguais e desigual para os desiguais à medida que se desigualam.

Quanto aos aspectos relativos à formatação, nota-se, claramente, ser esse o ponto em que a atuação dos revisores mostrou-se mais problemática. Considerando-se, como foi dito, tais aspectos de formatação/normalização sob uma perspectiva mais 
ampla - que vai desde a formatação básica do documento até o modo como se procede em relação às citações e à organização textual do trabalho acadêmico -, foi possível observar que, em todos os casos, persistiram problemas no artigo após a revisão.

Em relação à formatação dos elementos previstos pelas normas da ABNT, a atuação dos revisores limitou-se aos elementos mais básicos, deixando de lado aspectos importantes da estrutura do documento, o que evidencia que poucos revisores utilizam-se de todos os recursos disponíveis no processador de texto Word - como o recurso "Mostrar tudo" (Ctrl+*), que exibe marcas de formatação de caracteres não imprimíveis -, recursos estes que permitem verificar a estrutura profunda do documento, como ocorre, por exemplo, com a padronização de estilos e marcas de paragrafação. É o que se pode notar nos exemplos abaixo, que demonstram que apenas o R3 propôs alterações de formatação mais abrangentes:

R1:

1. Dos fatos

O objetivo da democracia é alcançar a igualdade jurídica e, para que essa igualdade possa se concretizar, devem-se levar em conta os iguais na medida de sua igualdade e os desiguais na medida se sua desigualdade.

[P2] Comentário: Sugiro colocar "Introdução" como titulo.

Formatado: Fonte: (Padrão) Times New Roman, $12 \mathrm{pt}$

Formatado: Fonte: (Padrão) Times New Roman, 12 pt

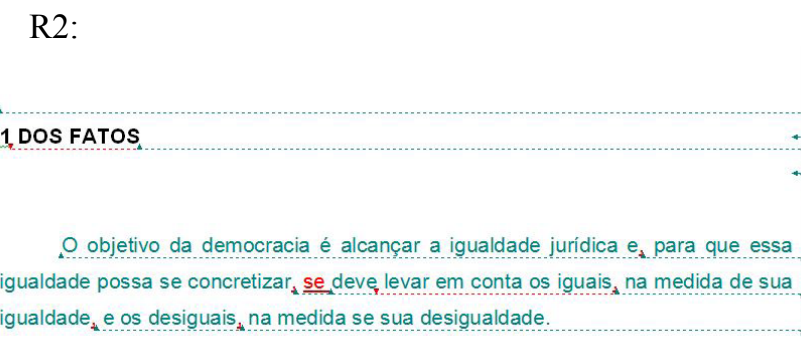

igualdade ${ }_{4}$ e os desiguais, na medida se sua desigualdade
Formatado: Fonte: (Padrão) Arial

Exduido: .

Formatado: Justificado, Espaço Depois de: 0 pt, Espaçamento entre linhas: 1,5 linhas

Formatado: Fonte: (Padrão) Arial, 12 pt

Formatado: Recuo: Primeira Inha: $1,25 \mathrm{~cm}$, Espaço Antes: 0 pt, Depois $1,25 \mathrm{~cm}$,
de: $0 \mathrm{pt}$

Formatado: Fonte: (Padrão) Arial

Formatado: Fonte: (Padrão) Arial

Formatado: Fonte: (Padrão) Arial

Formatado: Fonte: (Padrão) Arial

Excluído: -se

Formatado: Fonte: (Padrão) Arial

Formatado: Fonte: (Padrão) Arial

Formatado: Fonte: (Padrão) Arial 
R3:

1 DOS FATOS

O objetivo da democracia é alcançar a igualdade jurídica, sendo que, para que essa* igualdade possa se concretizar, os iguais devem ser levados em conta na medida de sua igualdade, e os desiguais, na medida se sua desigualdade.

R4:

1. Dos fatos

O objetivo da democracia é alcançar a igualdade jurídica Para que essa igualdade Formatado: Fonte: (Padrão) Times New Roman

Formatado: Fonte: (Padrão) Times New Roman, Realce

possa se concretizar, deve-se levar em conta os iguais na medida de sua igualdade e os Formatado: Fonte: (Padrão) Times desiguais na medida de sua desigualdade. 
R2:

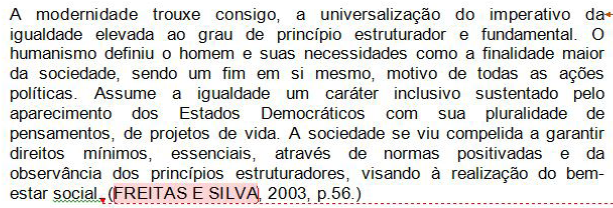

Formatado: Recuo: À esquerda: 4 cm, Espaço Antes: 0 pt, Depois de: 0 pt humanismo definiu o homem e suas necessidades como a finalidade maior da sociedade, sendo um fim em si mesmo, motivo de todas as ações porantir observância dos princípios estruturador de normas positivadas e da

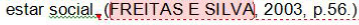

R3:

R4:
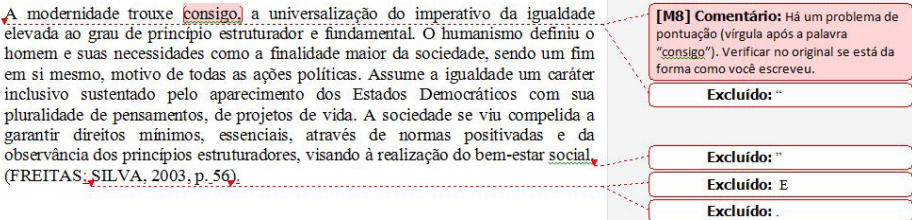
(FREITAS:SILVA, 2003, p. 56).

Outros aspectos relevantes foram deixados de lado pelos revisores, como, por exemplo, a dificuldade do autor em posicionar-se no texto diante das vozes dos autores citados, optando por um ocultamento sob o discurso relatado. ${ }^{4}$ Ora, considerando-se, como propõe Matencio (2003, p. 3), que o discurso citado, além de ser constitutivo de grande parte dos gêneros acadêmicos, tem "tanto a função de indicar o conhecimento que se tem do campo teórico, o qual fundamenta a seleção ou não de autores com os quais interagir e/ou basear, quanto a função de [...] mostrar a adesão ou não ao(s) autor(es) com o(s) qual(is) dialoga”, talvez, seja pertinente questionar em que medida tais aspectos deveriam ser contemplados pelo revisor. Em outros termos, retomando as questões que nortearam a análise das intervenções dos revisores, pode-se refletir não apenas sobre qual é a abrangência

4 Dificuldade que, de fato, pode ser considerada uma tendência em textos de conclusão de curso, evidenciada, por exemplo, nos estudos de Matencio (2002, 2003, 2004). Particularmente em relação a trabalhos de conclusão de curso na área de Direito, a mesma tendência foi verificada por Oliveira (2001). 
prevista pela própria atividade de revisão de textos acadêmicos, mas também sobre como os revisores se posicionam diante dessa abrangência e como esse posicionamento lida com as posições identitárias do sujeito autor, em face dos modos de dizer legitimados pela prática acadêmica.

\section{Considerações finais}

Certamente, os problemas teóricos que perpassam a atividade da revisão profissional de textos conduzem quase sempre ao mesmo impasse: até que ponto o revisor pode intervir no texto do outro? Desse questionamento, decorrem mesmo questões éticas, relacionadas ao problema da autoria - ainda que tais questões dependam, em grande parte, dos sistemas de valores de comunidades discursivas específicas, uma vez que a atuação de um revisor/preparador de textos é significativamente diversa, por exemplo, quando se têm em vista as demandas do mercado editorial, em que as intervenções no texto, por mais substanciais que sejam, têm implicações distintas sobre a questão da autoria.

Em suma, considerando-se a demanda crescente por serviços de revisão de textos acadêmicos e, ainda, o fato de a própria expansão do ensino superior trazer à tona problemas de escrita que remontam aos estágios básicos da formação escolar, existiria uma fronteira entre o domínio do ensino/formação acadêmica e a esfera de atuação do revisor? Existiria um limite para as atribuições da revisão, especialmente no caso da revisão dita resolutiva? Que limite seria esse? São perguntas, entre muitas outras, com as quais o revisor de textos acadêmicos inevitavelmente tem de lidar. Cumpre trazê-las não apenas para a prática, como também para as reflexões teóricas que têm sido empreendidas pela própria academia, pensando-as a partir de seus pontos de tangência e de suas implicações sobre outros aspectos, com os quais, o revisor se depara frequentemente. É o que se tentou fazer, ainda que brevemente, neste artigo. Talvez, mais importante do que uma resposta pontual a todas essas questões seja sua reformulação constante, incorporada ao próprio ato de revisar. 


\begin{abstract}
In this article, we seek to reflect essentially on the role of proofreaders who deal with academic-scientific texts, considering both the issue of the market demands for proofreading in this area and the broader aspects of scholarly practice. We believe that these aspects include both the procedures that guide linguistic-grammatical interventions by the proofreader as well as interventions on text standardization and formatting. These interventions include a wide range of factors, which are often critical for the recognition of a text as a scientifically valid communicative document. Articulated with this reflection we have a brief analysis of the way as four proofreaders (all of them graduated in Letters and with proofreading experience) undertook their actions in a scholarly article.
\end{abstract}

Keywords: Proofreading. Scholarly work. Proofreaders' performance. Text standardization/formatting.

\title{
Referências
}

AMOSSY, Ruth. O ethos na intersecção das disciplinas: retórica, pragmática, sociologia dos campos. In: AMOSSY, Ruth (Org.). Imagens de si no discurso: a construção do ethos. São Paulo: Contexto, 2005. p.119-144.

BRASIL. Lei Complementar $n^{0}$ 128, de 19 de dezembro de 2008. Disponível em: <http://www2.camara.leg.br/legin/fed/leicom/2008/leicomplementar-128-19dezembro-2008-584953-publicacaooriginal-107817-pl.html>. Acesso em: 25 abr. 2013.

BAKHTIN, Mikhail (VOLOCHÍNOV, Valentin Nikolaevich). Marxismo e filosofia da linguagem. 11. ed. São Paulo: Hucitec, 2004. Original publicado em 1929.

BRENTANI, Ricardo Renzo; CRUZ, Carlos Henrique de Brito (Coord.). Indicadores de ciência, tecnologia e inovação em São Paulo 2010. Fapesp, 2011. Disponível em: <http://www.fapesp.br/indicadores2010>. Acesso em: 17 mar. 2013.

DOBRA o número de publicações científicas no exterior. O Nacional, 24 fev. 2013. Disponível em: <http://www.onacional.com.br/geral/brasil/35128/ dobra $+\mathrm{o}+$ numero + de + publicacoes + cientificas + no + exterior $>$. Acesso em: 25 mar. 2013.

KOCH, Ingedore Villaça; ELIAS, Vanda Maria. Ler e compreender os sentidos do texto. São Paulo: Contexto, 2006. 
MARCUSCHI, Luiz Antonio. Produção textual, análise de gêneros e compreensão. São Paulo: Parábola, 2008.

MATENCIO, Maria de Lourdes Meirelles. Atividades de Retextualização em práticas acadêmicas: um estudo do resumo. Scripta, Belo Horizonte, v. 6, 2002.

MATENCIO, Maria de Lourdes Meirelles. Referenciação e Retextualização de textos acadêmicos. Um estudo do resumo e da resenha. In: CONGRESSO DA ABRALIN, 3., 2003. Anais... Rio de Janeiro: UFRJ, 2003. p. 1-10.

MATENCIO, Maria de Lourdes Meirelles. O recurso do discurso do outro em textos de alunos de Letras. In: INPLA, 14., 2004.

MONDADA, Lorenza; DUBOIS, Danièle. Construção dos Objetos de discurso e categorização: Uma abordagem dos processos de referenciação. In: CAVALCANTE, Mônica Magalhães et al. (Org.). Referenciação. São Paulo: Contexto, 2003.

OLIVEIRA, Jairo Venício Carvalhais. O discurso relatado como forma de posição identitária no gênero monográfico: reflexões para a atividade de revisão de textos. ReVeLe, n. 2, jan. 2011.

PRODUÇÃO científica no Brasil: um salto no número de publicações. Em discussão! Revista de audiências públicas do Senado Federal, v. 3, n. 12, set. 2012. Disponível em: <http://www.senado.gov.br/NOTICIAS/JORNAL/EM DISCUSSAO/inovacao/ investimento-inovacao-tecnologica-finep-pesquisadoresbrasil/producao-cientifica-no-brasil-um-salto-no-numero-de-publicacoes.aspx> . Acesso em: 25 mar. 2013.

RIBEIRO, Ana Elisa. Revisão de textos e "diálogo" com o autor: abordagens profissionais do processo de produção e edição textual. In: Intercom - Sociedade Brasileira de Estudos Interdisciplinares da Comunicação. Cong

resso Brasileiro de Ciências da Comunicação, XXXII., 2008, Curitiba, PR, 4-7 set. Disponível em: <http://goo.gl/zYGVD>. Acesso em: 15 mar. 2012.

SALGADO, Luciana Salazar. Ritos genéticos no mercado editorial: autoria e práticas de textualização. 2007. Tese (Doutorado) - Universidade Estadual de Campinas, Campinas, São Paulo, 2007.

SARAMAGO, José. História do Cerco de Lisboa. 5. ed. Lisboa: Ed. Caminho, 1989.

Submetido em: 17 de junho de 2015.

Aceito para publicação em: 06 de outubro de 2015. 
